\title{
Modelling of heat transfer process in condensing unit with titanium alloy tubes
}

\author{
Sergey Lavrinenko ${ }^{1, *}$, Pavel Polikarpov ${ }^{1}$, Anastasiya Matveeva ${ }^{1}$, and Vladimir Martyshev ${ }^{1}$ \\ ${ }^{1}$ National Research Tomsk Polytechnic University, 634050 Tomsk, Russia
}

\begin{abstract}
One of the most important units of heat transfer equipment of a nuclear power plant is the condenser. Currently, at the nuclear stations of concern "Rosenergoatom" work is actively underway to replace the tubes of copper containing alloys to various steels or titanium alloys. Also, active work is underway on modernization of heat-exchange equipment of operating units. It is necessary to make the modelling of the parameters of condenser, to ensure that after the upgrade, the unit will continue operating normally. For this purpose, was created the model of module of tube bundle of condenser unit of K-33160 with tubes of titanium alloy. The modelling process is based on the equation of heat balance. In this work were modelled condenser of NPP of K-33160 with WWER-1000 reactor and the tubes of a titanium alloy VT0-1. The calculation was carried out for three presented methods and the error was less than $2 \%$.
\end{abstract}

\section{Introduction}

At present, Rosenergoatom's nuclear power plants are actively working on the modernization of existing equipment, in particular, replacement of tubes from copperbearing alloys to various steel or titanium alloys [1,2]. This is due to the fact that the copper that contained in the heat-exchange surfaces washed out and is being eroded by the working environment of the second circuit, in which the hydrazine is dosed, during the technological process.

The dosage of hydrazine in the working environment is to protect internal surfaces of equipment and pipelines, because hydrazine, reacting with the iron, forms a resistant oxide film that is called magnetite $\left(\mathrm{Fe}_{3} \mathrm{O}_{4}\right)$ and neutralizes the oxygen that is got in the circuit.

But, at the same time, hydrazine under high temperature (more than $100{ }^{\circ} \mathrm{C}$ ) decomposes to ammonia, which dissolves the copper contained in the copper-nickel alloys ("MNZH-5").

As a result, the dissolved copper gets into the water of the second circuit and causes corrosion of the tubes of heat transfer equipment.

These circumstances forced the project organizations to seek new materials for heat transfer surfaces of the equipment. All equipment (high pressure heaters, low pressure heaters, heat exchangers, ejectors, etc.) on the power plant units that are in the process of

\footnotetext{
* Corresponding author: $\underline{\operatorname{serg} 86 @ \text { tpu.ru }}$
} 
construction, made of stainless steel, tube condensers made of titanium alloys. Also, active work is underway on modernization of heat-exchange equipment of operating units $[3,4]$.

\section{Methods of research}

One of the most important units of heat transfer equipment of a nuclear power plant is the condenser. It is necessary to make the modelling of the parameters of condenser, to ensure that after the upgrade, the unit will continue operating normally. For this purpose, was created the model of module of tube bundle of condenser unit of K-33160 with tubes of titanium alloy (Fig. 1).

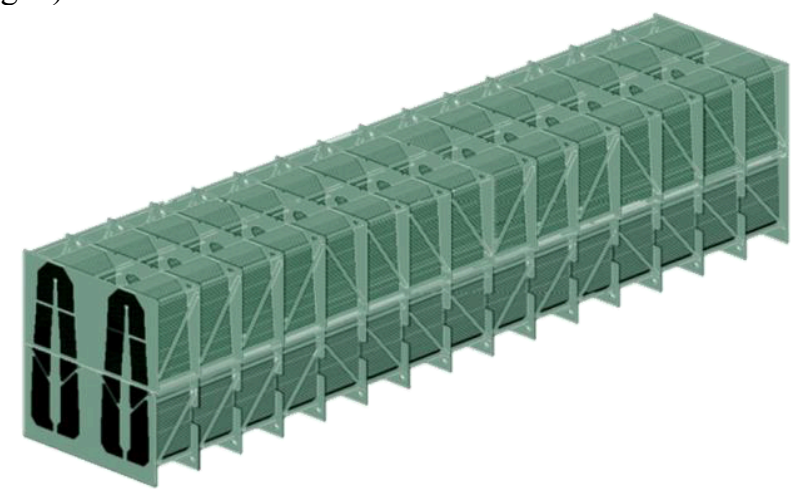

Fig. 1. The module of tube bundle of condenser.

Due to the change of material of tubes, changing the heat transfer coefficient, which would entail a change in the thermal capacity of the condenser, which is unacceptable. In order to avoid this impact, it is necessary to choose the appropriate area. The modelling process is based on the equation of heat balance [5]:

$$
Q_{\mathrm{c}}=G_{\mathrm{s}}\left(h_{\mathrm{c}}-h_{\mathrm{c}}^{\prime}\right)=G_{\mathrm{w}} c_{\mathrm{p}}\left(t_{\text {out }}-t_{\text {in }}\right)=k \cdot F \cdot \delta t,
$$

where

$Q_{\mathrm{c}}$ - thermal capacity;

$G_{\mathrm{s}}-$ steam flow to the condenser;

$h_{\mathrm{c}}$ - enthalpy of steam;

$h_{\mathrm{c}}$ - enthalpy of water;

$G_{\mathrm{w}}-$ cooling water flow;

$c_{\mathrm{p}}$ - heat capacity at constant pressure;

$t_{\text {in }}, t_{\text {out }}$ - temperature of the cooling water;

$k=\left(R_{\mathrm{w}}+R_{\mathrm{t}}+R_{\mathrm{s}}\right)^{-1}-$ heat transfer coefficient;

$R_{\mathrm{w}}$ - thermal resistance of the cooling water;

$R_{\mathrm{t}}$ - thermal resistance of the tube wall;

$R_{\mathrm{s}}$ - thermal resistance of the steam;

$F$ - heat transfer area;

$\delta t$ - average logarithmic thermal pressur.

The heat transfer from the condensing steam to the cooling water through the heat exchange surface, belongs to the complex type of heat transfer. Considering the heat transfer coefficient as the reciprocal of the sum of the thermal resistances in the path of heat transfer from the steam to the cooling water. 
The influence of sediments on both sides of the tube can be neglected, as the tubes are new, and unlike copper-Nickel alloy, the amount of deposits is significantly reduced, in case of long term work.

Determination of thermal resistance of water and wall of tube are not particularly hard:

$$
\begin{gathered}
R_{\mathrm{t}}=\delta_{\mathrm{t}} / \lambda_{\mathrm{t}} \\
R_{\mathrm{t}}=\left(0.023 \operatorname{Re}_{\mathrm{w}}{ }^{0.8} \operatorname{Pr}_{\mathrm{w}}{ }^{0.4}\left(\lambda_{\mathrm{w}} / \mathrm{d}_{\mathrm{in}}\right)\right)^{-1},
\end{gathered}
$$

where

$\delta_{\mathrm{t}}$ - tube wall thickness;

$\lambda_{\mathrm{t}}, \lambda_{\mathrm{w}}-$ coefficient of thermal conductivity of tube, water.

It is necessary to know appropriate geometric and thermophysical parameters of the water and the wall.

The definition of thermal resistance from steam side of condensate is strongly complicated by the joint influence of many factors, the most important of which is the phenomenon of the flooding of the lower tubes with the condensate. It should be borne in mind that the main steam parameters will substantially change according to the movement in the tube bundle.

The heat transfer coefficient from the steam to the surface of the tube bundle:

$$
\alpha_{\mathrm{s}}=28.3 \Pi^{0.08} N u^{-0.58} / \alpha_{\mathrm{Nu}},
$$

where

$\Pi=\rho_{\mathrm{s}} W_{\mathrm{s}}^{2} /\left(\rho_{\mathrm{c}} g d_{\mathrm{out}}\right)-$ dimensionless number;

$\rho_{\mathrm{s}}, \rho_{\mathrm{c}}$ - density of steam and condensate;

$W_{\mathrm{s}}$ - flow rate of steam;

$N u=\alpha_{\mathrm{Nu}} d_{\mathrm{out}} / \lambda_{\mathrm{c}}-$ Nusselt number for condensation of stationary;

$\alpha_{\mathrm{Nu}}=0.725 \mathrm{Ga} \cdot \operatorname{Pr} \cdot K \cdot \lambda_{\mathrm{c}} / d_{\text {out }}$;

$\lambda_{\mathrm{c}}$ - coefficient of thermal conductivity of condensate;

$G a, \operatorname{Pr}, K$ - number of Galileo, Prandtl and phase transition.

Also the heat transfer coefficient was determined by the simplified methods [6].

\subsection{Method of "VTI"}

$$
k=4070 \cdot a \cdot \Phi_{\mathrm{w}} \Phi_{\mathrm{t}} \Phi_{\mathrm{z}} \Phi_{\mathrm{d}}
$$

where

$a$ - coefficient of condition of heat exchange surface;

$\Phi_{\mathrm{w}}-$ factor of rate;

$\Phi_{\mathrm{t}}$ - factor of temperature;

$\Phi_{\mathrm{z}}$ - factor of number of cycles of flowing of cooling water;

$\Phi_{\mathrm{d}}-$ factor of steam load.

\subsection{Method of "ITO"}

$$
k=k_{\mathrm{o} 1} \beta_{\mathrm{t}} \beta_{\mathrm{m}}
$$

where

$k_{\mathrm{o} 1}$ - coefficient of heat transfer in case of the temperature of water at the outlet is $21^{\circ} \mathrm{C}$;

$\beta_{\mathrm{t}}$ - correction for temperature of output water;

$\beta_{\mathrm{m}}-$ coefficient that take into account the wall thickness and material. 
For condensers, that were made in Russia, required one additional amendment to take account of the pollution of the tube: $0.75-0.85$.

In order to be able to determine the coefficient of heat transfer, it is necessary to set the parameters of tubes:

Table 1. Parameters of tubes.

\begin{tabular}{|c|c|c|c|c|c|c|}
\hline $\begin{array}{c}\text { Material of } \\
\text { the tubes }\end{array}$ & $\begin{array}{c}\mathbf{d}_{\text {in } 1}, \\
\mathbf{m m}\end{array}$ & $\begin{array}{c}\mathbf{d}_{\text {out } 1}, \\
\mathbf{m m}\end{array}$ & $\begin{array}{c}\mathbf{N}_{\mathbf{t} 1}, \\
\mathbf{p c s}\end{array}$ & $\begin{array}{c}\mathbf{d}_{\text {in2 }}, \\
\mathbf{m m}\end{array}$ & $\begin{array}{c}\mathbf{d}_{\text {out } 2}, \\
\mathbf{m m}\end{array}$ & $\begin{array}{c}\mathbf{N}_{\mathbf{t 1}}, \\
\mathbf{p c s}\end{array}$ \\
\hline VT0-1 & 27 & 28 & 26688 & 26.6 & 28 & 252 \\
\hline
\end{tabular}

\section{Results}

The results of determination of heat transfer coefficient of the condenser K-33160 with titanium tubes by different methods is presented in table 2 .

Table 2. Heat transfer coefficient.

\begin{tabular}{|c|c|c|c|}
\hline $\begin{array}{c}\text { Material of } \\
\text { the tubes }\end{array}$ & $\begin{array}{c}\text { According to } \\
\text { the thermal } \\
\text { resistances }\end{array}$ & VTI & ITO \\
\hline $\begin{array}{c}\mathbf{K}, \\
\mathbf{W} /\left(\mathbf{m}^{\mathbf{2}} \mathbf{K}\right)\end{array}$ & 5540 & 5614 & 5648 \\
\hline $\mathbf{\Delta , \%}$ & - & 1.34 & 1.96 \\
\hline
\end{tabular}

\section{Conclusion}

The process of heat exchange in the condenser is quite complicated, and its calculation is difficult. It is much complicates the process of replacing the tubes and their calculation on various parameters of the environment. In this work were modelled condenser of NPP of K33160 with WWER-1000 reactor and the tubes of a titanium alloy "VT0-1". The calculation was carried out for three presented methods and the error was less than $2 \%$.

\section{References}

1. E. Pavelyev, S. Lavrinenko, MATEC Web Conf. 72, 01085 (2016)

2. V.A. Ruppel, Yu.S. Tretyakova, S.V. Lavrinenko, A.A. Matveeva, V.N. Martyshev, MATEC Web Conf. 37, 01059 (2015)

3. N. Galashov, S. Tsibulskiy, A. Kiselev, MATEC Web Conf. 72, 01029 (2016)

4. N. Galashov, S. Tsibulskii, A. Matveev, V. Masjuk, EPJ Web Conf. 110, 01019 (2016)

5. Yu.M. Brody, M.A. Nirenstein, Calculation of heat exchangers for steam turbine units (USTU, 2001)

6. S.A. Yankovsky, V.E. Gubin, A.A. Tolokolnikov, A.V. Zenkov, IFOST, 7884252 (2017) 